\title{
The electrical characterization of grain boundaries in ultra-fine grained Y-TZP
}

\author{
C. S. Chen, M. M. R. Boutz, B. A. Boukamp, A. J. A. Winnubst, K. J. de Vries \\ and A. J. Burggraaf \\ Laboratory of Inorganic Chemistry, Catalysis and Inorganic Materials Science, Faculty of Chemical Technology, \\ University of Twente, P.O. Box 217, 7500AE, Enschede (Netherlands)
}

\begin{abstract}
Starting from a sinter reactive powder prepared by a gel precipitation technique, dense, ultra-fine grained (100-200 $\mathrm{nm})$ yttria stabilized tetragonal zirconia ceramics were obtained by sinter forging at a temperature of $1100^{\circ} \mathrm{C}$ or by pressureless sintering at $1150^{\circ} \mathrm{C}$. The pressureless sintered compacts were subjected to further heat treatments at temperatures of $1250-1450^{\circ} \mathrm{C}$ or compressive deformation at $1250^{\circ} \mathrm{C}$ under uniaxial stresses of $20-100 \mathrm{MPa}$. The obtained samples were characterized mainly by impedance spectroscopy. After compressive deformation a decrease in grain boundary resistivity was found which increased with applied stress. This can be interpreted in terms of a decrease in impurity segregation and a partial removal by compressive deformation of a poorly conducting amorphous film around the grains. It was also found that the grain boundary resistivity of samples sintered at $1150^{\circ} \mathrm{C}$ could be considerably reduced by further pressureless heat treatments at temperatures above $1250^{\circ} \mathrm{C}$. This effect is probably owing to dewetting of the grain boundary and dissolution of grain boundary impurities into the bulk of the grains.
\end{abstract}

\section{Introduction}

At present there is increasing interest in nanoscale ceramics [1]. As indicated by Burggraaf [1] and Burggraaf et al. [2], the characteristics of ceramics with grain sizes in the nanometer range are (i) a large fraction of atoms is contained in the grain boundary region or in a region with characteristic physical length (Debye length, domain size), and (ii) transport properties are changed, e.g. enhanced diffusivity and deformability. One of these nanoscale ceramics under investigation in our laboratory is yttria stabilized tetragonal zirconia polycrystal (Y-TZP). Boutz et al. [3] have reported on the preparation of $2.6 \mathrm{~mol} \% \mathrm{Y}_{2} \mathrm{O}_{3}-\mathrm{ZrO}_{2}$ (2.6Y-TZP) with a grain size of $100 \mathrm{~nm}$ and a relative density of $94 \%$ using sinter-forging. The particle sizes in the starting green compacts were around 7-10 nm, the pore sizes were around $6 \mathrm{~nm}$. It is expected that these ultrafine grained ceramics may possess special grain boundary related properties.

It is recognized that the presence of an amorphous silicate phase at grain boundaries in Y-TZP has a strong influence on both the electrical [4] and creep [5] properties. The distribution of this amorphous phase strongly depends on its composition and the thermomechanical history. Several ceramic processing parameters such as heat treatment temperature, cooling rate, pressure [6] and ambient [7] all affect the nature and location of the grain boundary phase.

In the present investigation the influence of processing parameters (temperature, pressure) on the grain boundary properties of Y-TZP (initial grain size 100-200 nm) was studied. Impedance spectroscopy (IS), in combination with transmission electron microscopy (TEM) and X-ray photoelectron spectroscopy (XPS), was used to gain a better insight into the grain boundary properties of ultra-fine grained Y-TZP.

\section{Experimental details}

\subsection{Preparation and processing}

The ultra-fine grained starting powders, $2.6 \mathrm{~mol} \% \mathrm{Y}_{2} \mathrm{O}_{3}-\mathrm{ZrO}_{2}$ with a crystallite size of $7-10 \mathrm{~nm}$, were prepared by a gel precipitation technique using metal chlorides as precursor chemicals. Details of the synthesis have been presented elsewhere [8]. Of these powders cylindrical compacts were prepared by cold isostatic compaction ( $400 \mathrm{MPa}$ ).

In order to improve the strength of the green compact samples for the sinter forging experiments a presintering step was carried out by heating to $950^{\circ} \mathrm{C}$ at a rate of $120^{\circ} \mathrm{C} \mathrm{h}^{-1}$, immediately followed by cooling. Dimensions after the pre-sintering step were typically 
$15.7 \mathrm{~mm}$ (height) $\times 7.3 \mathrm{~mm}$ (diameter). Sinter forging tests were performed in air at $1100^{\circ} \mathrm{C}$ under constant load corresponding to initial stresses of 28,58 and 84 $\mathrm{MPa}$ respectively. Further details are given elsewhere [3].

Samples for hot forging experiments were prepared by sintering for $10 \mathrm{~h}$ in air at $1150^{\circ} \mathrm{C}$, followed by machining to identical dimensions $(6.5 \mathrm{~mm}$ diameter and $8.5 \mathrm{~mm}$ height). Compression was carried out at $1250^{\circ} \mathrm{C}$ under constant loads corresponding to initial stresses of 20,60 and $100 \mathrm{MPa}$ respectively. When the sample height was reduced to half the original size the pressure was removed and the sample cooled to room temperature at a rate of $300^{\circ} \mathrm{Ch} \mathrm{h}^{-1}$.

The samples that were sintered at $1150^{\circ} \mathrm{C}$ for $10 \mathrm{~h}$ without applying pressure were subjected to further heat treatments in air at temperatures between 1250 and $1450^{\circ} \mathrm{C}$ for $3 \mathrm{~h}$, followed by cooling at a rate of $300^{\circ} \mathrm{C} \mathrm{h}^{-1}$.

\subsection{Characterization of the $Y-T Z P$}

The grain diameter was determined by the linear intercept technique [9] from SEM images of polished and subsequently thermally etched samples.

For the impedance measurements disk-shaped samples were cut with a diameter of $5.1 \mathrm{~mm}$ and a thickness of $3.0 \mathrm{~mm}$. After polishing, a $200 \mathrm{~nm}$ thick platinum layer was deposited onto both sides by d.c. sputtering. The electrodes were cured and stabilized by heat treatment at $750-950^{\circ} \mathrm{C}$ for $2 \mathrm{~h}$ and cooling at a rate of $300^{\circ} \mathrm{C} \mathrm{h}^{-1}$. The impedance was measured using a Solartron 1255 frequency response analyzer over the frequency range $1-10^{6} \mathrm{~Hz}$ and in the temperature range $300-590^{\circ} \mathrm{C}$. Only results obtained at $341^{\circ} \mathrm{C}$ are presented here.

The impedance spectra were analysed using the non-linear least squares impedance analysis package Equivalent Circuit [10]. As model function the equivalent circuit proposed by Bauerle [11] was used. By simultaneously fitting all equivalent circuit parameters in the NLLSF procedure, the bulk and grain boundary resistances can be separated [10]. The grain boundary resistivity is affected by the impurity segregation at the grain boundaries as well as by the size of the grains. Hence, in order to account for both effects, the grain boundary resistivity was corrected for grain size. This grain boundary resistivity per unit surface area $R_{\mathrm{sp}}$ is calculated by [12]

$R_{\mathrm{sp}}=R_{\mathrm{gb}}{ }^{\mathrm{mac}} D_{\mathrm{g}}$

where $R_{\mathrm{gb}}{ }^{\text {mac }}$ is the macroscopic grain boundary resistivity normalized for specimen dimensions, and $D_{\mathrm{g}}$ is the grain size.

\section{Results and discussion}

\subsection{Grain boundary properties of the deformed $Y-T Z P$}

In Fig. 1 the impedance spectra are shown for $2.6 \mathrm{Y}-$ TZP samples prepared by sinter forging at $1100^{\circ} \mathrm{C}$ under respectively 28,58 and $84 \mathrm{MPa}$ initial stress. The grain sizes for these samples were in the range 100-130 nm. In Fig. 2 the impedance spectra are shown for three $2.6 \mathrm{Y}-\mathrm{TZP}$ samples treated by hot forging at $1250^{\circ} \mathrm{C}$ at initial stresses of respectively 20 , 60 and $100 \mathrm{MPa}$. The grain sizes were in the range 210-240 nm. Samples that were deformed either by sinter forging or by hot forging showed, with increasing initial stress, a decrease in the corrected grain boundary resistivity $R_{\text {sp. }}$. This effect is most pronounced for the highest stress applied, as can be seen in Fig. 3 .

Although samples prepared by sinter forging at $1100^{\circ} \mathrm{C}$ and samples treated by hot forging at $1250^{\circ} \mathrm{C}$ showed similar trends of a decrease in $R_{\mathrm{sp}}$ with increas-

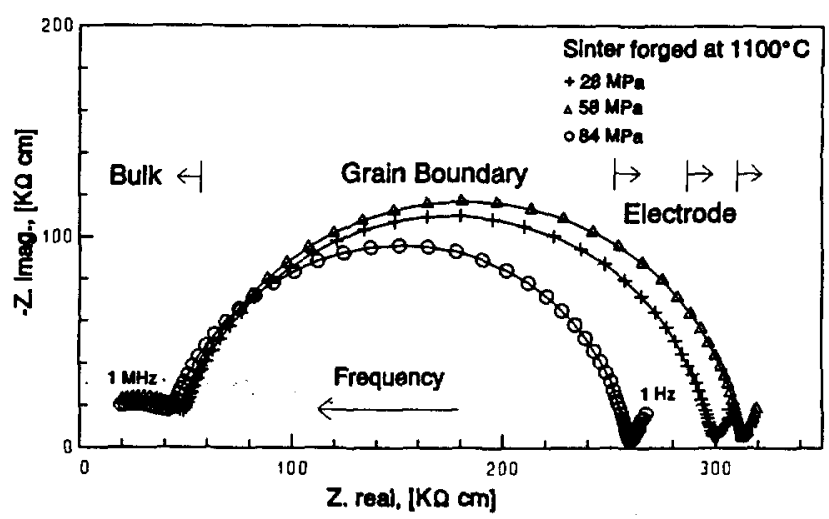

Fig. 1. Impedance spectra for $2.6 \mathrm{~mol}^{2} \mathrm{Y}_{2} \mathrm{O}_{3}-\mathrm{ZrO}_{2}$ ceramics prepared by sinter forging at $1100^{\circ} \mathrm{C}$ under various initial stresses, measured at $341^{\circ} \mathrm{C}$ in air.

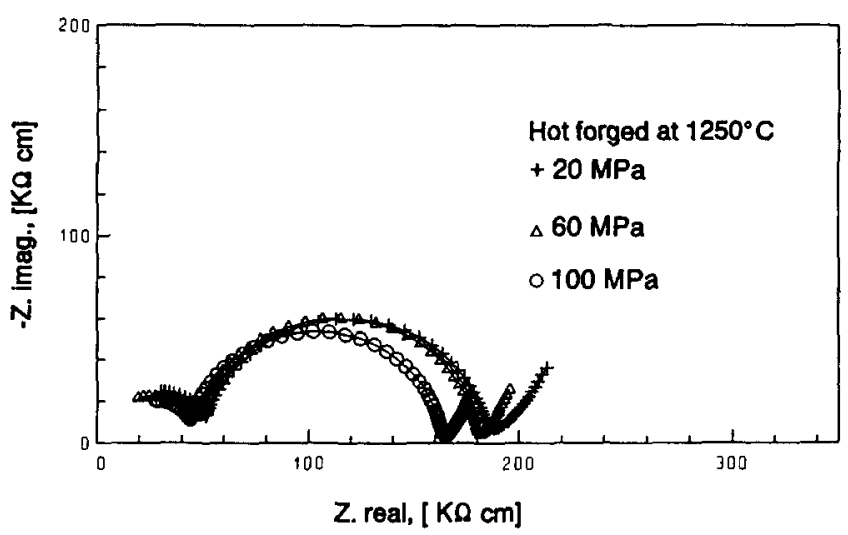

Fig. 2. Impedance spectra for $2.6 \mathrm{~mol} \% \mathrm{Y}_{2} \mathrm{O}_{3}-\mathrm{ZrO}_{2}$ ceramics deformed at $1250^{\circ} \mathrm{C}$ under various initial uniaxial stresses, measured at $341^{\circ} \mathrm{C}$ in air. 
ing stress, the mechanism of each trend may be quite different. In the case of sinter forging, the decrease in $R_{\mathrm{sp}}$ should be attributed to a decrease in the segregation of impurities. As demonstrated by Boutz et al. [3], sinter forging allows a reduction in both the sintering temperature and sintering time required to obtain dense ceramics. The important advantages of these reductions are (i) grain growth is markedly suppressed, and (ii) there is less time available for impurities to segregate to the grain boundaries, forming amorphous films around the grains. By increasing the stress imposed on the sintering compact the sintering temperature can be lowered and the sintering time required to obtain a dense ceramic, can be reduced Consequently the extent to which segregation can take place is reduced, hence $R_{\mathrm{sp}}$ will be decreased.

Samples obtained by pressureless sintering at $1150^{\circ} \mathrm{C}$, which were to be used in the hot forging experiments, contained a continuous film around the grains which impedes the transport of oxygen ions across the grain boundaries. After compressive deformation at $1250^{\circ} \mathrm{C}$, this film became discontinuous. Impurities in the films were partially removed from the grain boundaries, resulting in a reduction in $R_{\mathrm{sp}}$. In a separate investigation by Boutz [13], using TEM and XPS, some direct evidence was provided to support the above explanation. The TEM observations showed that a continuous film (thickness less than or equal to 1 $\mathrm{nm}$ ) of an amorphous intergranular phase existed in the as-sintered materials, while this amorphous phase was absent at certain grain boundaries after deformation. XPS analysis revealed that the average grain boundary concentrations of yttrium, aluminium and silicon were decreased after compressive deformation. This effect is most pronounced in the samples deformed at the higher stresses.

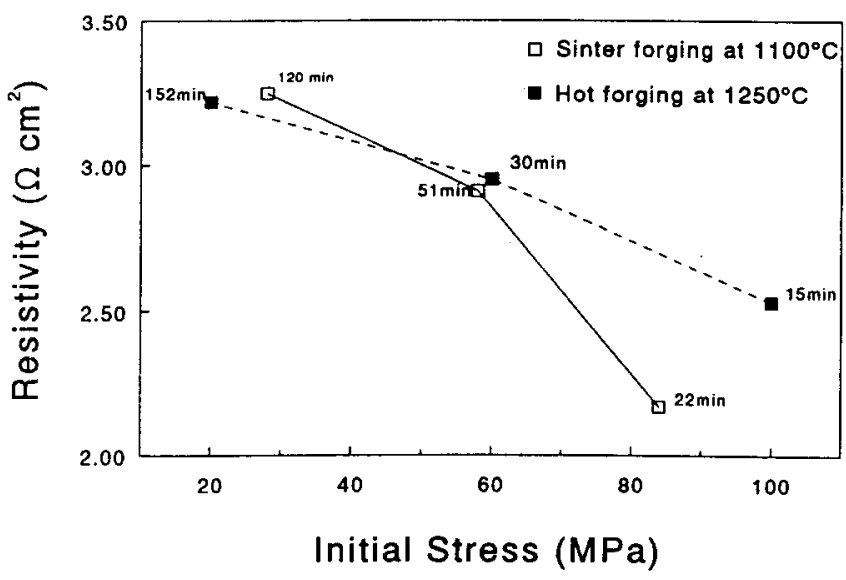

Fig. 3. Corrected grain boundary resistivity for the deformed $2.6 \mathrm{~mol}_{\%} \mathrm{Y}_{2} \mathrm{O}_{3}-\mathrm{ZrO}_{2}$ ceramics as a function of initial stress and processing time. Temperature is $341^{\circ} \mathrm{C}$.

\subsection{Grain boundary properties of $Y-T Z P$ heat treated at various temperatures}

2.6Y-TZP ceramics sintered at $1150^{\circ} \mathrm{C}$ for $10 \mathrm{~h}$ were further pressureless heat treated at temperatures of $1250-1450{ }^{\circ} \mathrm{C}$ for $3 \mathrm{~h}$. Figure 4 shows the impedance spectra of the heat treated Y-TZP ceramics. As shown in Fig. 5, the corrected grain boundary resistivity $R_{\mathrm{sp}}$ decreases sharply after heat treatment at $1250^{\circ} \mathrm{C}$ while the bulk resistivity remains almost unchanged. This possibly indicates that dewetting of the grain boundaries takes place, resulting in cleaning of the grain boundaries [14]. Furthermore, impurities such as iron and aluminium, initially present at the grain boundaries, will dissolve into the bulk of the grains at higher temperatures, as has been demonstrated by Hughes and Badwal [15].

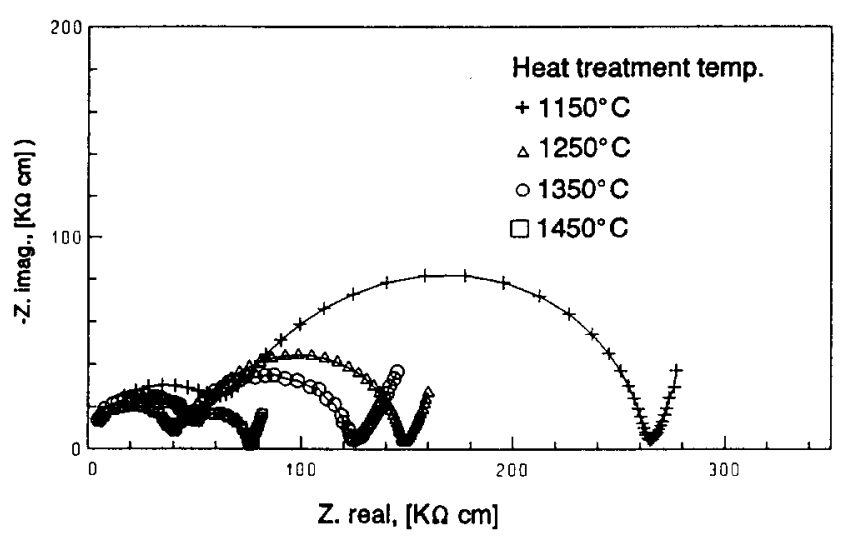

Fig. 4. Impedance spectra for $2.6 \mathrm{~mol} \% \mathrm{Y}_{2} \mathrm{O}_{3}-\mathrm{ZrO}_{2}$ ceramics pressureless heat treated at different temperatures for $3 \mathrm{~h}$, measured at $341^{\circ} \mathrm{C}$ in air.

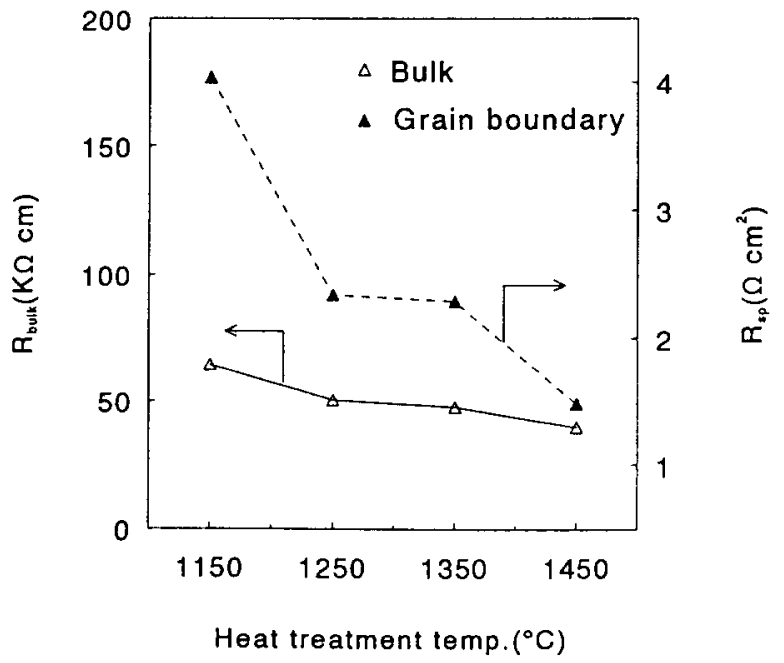

Fig. 5. Bulk resistivity and corrected grain boundary resistivity of $2.6 \mathrm{~mol} \% \mathrm{Y}_{2} \mathrm{O}_{3}-\mathrm{ZrO}_{2}$ pressureless heat treated at different temperatures, measured at $341^{\circ} \mathrm{C}$ in air. 


\section{Conclusions}

Dense, ultra-fine grained (100-130 nm) Y-TZP ceramics were prepared by sinter forging at a temperature of $1100^{\circ} \mathrm{C}$. Examination of the grain boundaries by impedance spectroscopy indicated that segregation of the impurities was suppressed owing to a lowering of the sintering temperature and a shortening of the required sintering time, which is a consequence of the exertion of uniaxial stress on the sintering body.

After compressive deformation at $1250^{\circ} \mathrm{C}$ the pressureless sintered samples showed a decrease in the grain boundary resistivity, revealing that a continuous amorphous film which is formed during sintering at $1150^{\circ} \mathrm{C}$ and which is rich in impurities can be partially removed from the grain boundaries, becoming discontinuous. This improves the transport of oxygen ions across the grain boundaries.

The grain boundary resistivity of the sample pressureless sintered at $1150^{\circ} \mathrm{C}$ could also be considerably reduced by further heat treatment at temperatures above around $1250^{\circ} \mathrm{C}$. This effect is probably due to dewetting of the grain boundaries and dissolution of grain boundary impurities into the bulk of the grains.

\section{Acknowledgement}

The investigations were supported by the Netherlands Foundation for Chemical Research (SON) with financial aid from the Netherlands Organization for Scientific Research (NWO).

\section{References}

1 A. J. Burggraaf, J. Eur. Ceram. Soc., 9 (1992) 245.

2 A. J. Burggraaf, K. Keizer and B. A. van Hassel, Nanophase ceramics, membranes and ion implanted layers. In L. C. Dufour, C. Marty and G. Petot-Ervas (eds.), Surfaces and Interfaces of Ceramic Materials, Kluwer, Dordrecht, 1989, pp. 705-725.

3 M. M. R. Boutz, A. J. A. Winnubst, A. J. Burggraaf, M. Nauer and C. Carry, in S. P. S. Badwal, M. J. Bannister and R. H. J. Hannink (eds.), Low temperature sinter-forging of Y-TZP ceramics, Proc. Zirconia V, Melbourne, August 1991, Australian Ceramic Society, 1993, in press.

4 S. P. S. Badwal, J. Drennan and A. E. Hughes, Segregation in oxygen-ion conducting solid electrolytes and its influence on electrical properties. In J. Nowotny (ed.), Science of Ceramic Interfaces, Elsevier, Amsterdam, 1991, pp. 227-285.

5 C. Carry, Microstructure, grain boundaries and superplasticity in fine grained ceramics. In $\mathbf{M}$. Mayo, $\mathbf{M}$. Kobayashi and J. Wadsworth (eds.), Superplasticity in Metals, Ceramics and Intermetallics, Mater. Res. Soc. Symp. Proc., $196(1990) 313$.

6 S. P. S. Badwal, F. T. Ciacchi, M. V. Swain and V. Zelizko, $J$. Am. Ceram. Soc., 73 (1990) 2505.

7 S. P. S. Badwal and A. E. Hughes, J. Eur. Ceram. Soc., 9 (1992) 115.

8 W. Groot Zevert, A. J. A. Winnubst, G. S. A. M. Theunissen and A. J. Burggraaf, J. Mater. Sci., 25 (1990) 3449.

9 M. I. Mendelson, J. Am. Ceram. Soc., 52 (1969) 443.

10 B. A. Boukamp, Solid State Ionics, 18-19(1986) 136.

11 J. E. Bauerle, J. Phys. Chem. Solids, 30 (1969) 2657.

12 M. Miyayama and H. Yanagida, J. Am. Ceram. Soc., 67 (1984) C194.

13 M. M. R. Boutz, Internal Rep. CT92/182/128, 1992 (University of Twente, 7500AE Enschede).

14 T. Stoto, M. Nauer and C. Carry, J. Am. Ceram. Soc., 74 (1991) 2615.

15 A. E. Hughes and S. P. S. Badwal, Solid State Ionics, 46 (1991) 265. 